\title{
Review Article \\ Regulation of Tight Junctions in Upper Airway Epithelium
}

\author{
Takashi Kojima, ${ }^{1}$ Mitsuru Go, ${ }^{2}$ Ken-ichi Takano, ${ }^{2}$ Makoto Kurose, ${ }^{2}$ Tsuyoshi Ohkuni, \\ Jun-ichi Koizumi, ${ }^{2}$ Ryuta Kamekura, ${ }^{2}$ Noriko Ogasawara, ${ }^{2}$ Tomoyuki Masaki, ${ }^{2}$ \\ Jun Fuchimoto, ${ }^{1}$ Kazufumi Obata, ${ }^{1,2}$ Satoshi Hirakawa, ${ }^{1,3}$ Kazuaki Nomura, ${ }^{1,2}$ \\ Takashi Keira, ${ }^{1,2}$ Ryou Miyata, ${ }^{1,2}$ Nobuhiro Fujii, ${ }^{4}$ Hiroyuki Tsutsumi, ${ }^{3}$ \\ Tetsuo Himi, ${ }^{2}$ and Norimasa Sawada ${ }^{1}$ \\ ${ }^{1}$ Department of Pathology, Sapporo Medical University School of Medicine, Sapporo 060-8556, Japan \\ ${ }^{2}$ Department of Otolaryngology, Sapporo Medical University School of Medicine, Sapporo 060-8556, Japan \\ ${ }^{3}$ Department of Pediatrics, Sapporo Medical University School of Medicine, Sapporo 060-8556, Japan \\ ${ }^{4}$ Department of Microbiology, Sapporo Medical University School of Medicine, Sapporo 060-8556, Japan \\ Correspondence should be addressed to Takashi Kojima; ktakashi@sapmed.ac.jp
}

Received 7 July 2012; Accepted 29 August 2012

Academic Editor: Mouldy Sioud

Copyright (C) 2013 Takashi Kojima et al. This is an open access article distributed under the Creative Commons Attribution License, which permits unrestricted use, distribution, and reproduction in any medium, provided the original work is properly cited.

The mucosal barrier of the upper respiratory tract including the nasal cavity, which is the first site of exposure to inhaled antigens, plays an important role in host defense in terms of innate immunity and is regulated in large part by tight junctions of epithelial cells. Tight junction molecules are expressed in both $\mathrm{M}$ cells and dendritic cells as well as epithelial cells of upper airway. Various antigens are sampled, transported, and released to lymphocytes through the cells in nasal mucosa while they maintain the integrity of the barrier. Expression of tight junction molecules and the barrier function in normal human nasal epithelial cells (HNECs) are affected by various stimuli including growth factor, TLR ligand, and cytokine. In addition, epithelial-derived thymic stromal lymphopoietin (TSLP), which is a master switch for allergic inflammatory diseases including allergic rhinitis, enhances the barrier function together with an increase of tight junction molecules in HNECs. Furthermore, respiratory syncytial virus infection in HNECs in vitro induces expression of tight junction molecules and the barrier function together with proinflammatory cytokine release. This paper summarizes the recent progress in our understanding of the regulation of tight junctions in the upper airway epithelium under normal, allergic, and RSV-infected conditions.

\section{Introduction}

The epithelium in the upper respiratory consists of pseudostratified ciliated columnar epithelial cells, including $M$ cells (membranous or microfold cells), which are specialized for antigen uptake and form a continuous barrier against a wide variety of exogenous antigens [1-5], and dendritic cells (DCs), which take up transported antigens via $\mathrm{M}$ cells and present antigens for $\mathrm{CD}^{+}{ }^{+} \mathrm{T}$ cells, while they maintain the integrity of the airway epithelial barrier [6-8]. The epithelium plays a crucial role as an interface of adaptive responses and innate responses via tight junctions to prevent invasion of inhaled environmental agents such as allergens and pathogens (Figure 1). In addition, in the human nasal mucosa of allergic rhinitis or virus infection, dynamic changes of tight junctions have been known.

\section{Tight Junctions in Epithelium}

The airway epithelium of the human upper respiratory mucosa acts as the first physical barrier that protects against inhaled substances and pathogens $[9,10]$. The epithelium is a highly regulated and impermeable barrier exclusively formed by tight junctions $[9,10]$.

Tight junctions, the most apically located of the intercellular junctional complexes, inhibit solute and water flow through the paracellular space (termed the "barrier" function) $[11,12]$. They also separate the apical from the basolateral cell surface domains to establish cell polarity (termed the "fence" function) $[13,14]$. Recent evidence suggests that tight junctions also participate in signal transduction mechanisms that regulate epithelial cell proliferation, gene expression, differentiation, and morphogenesis [15]. 


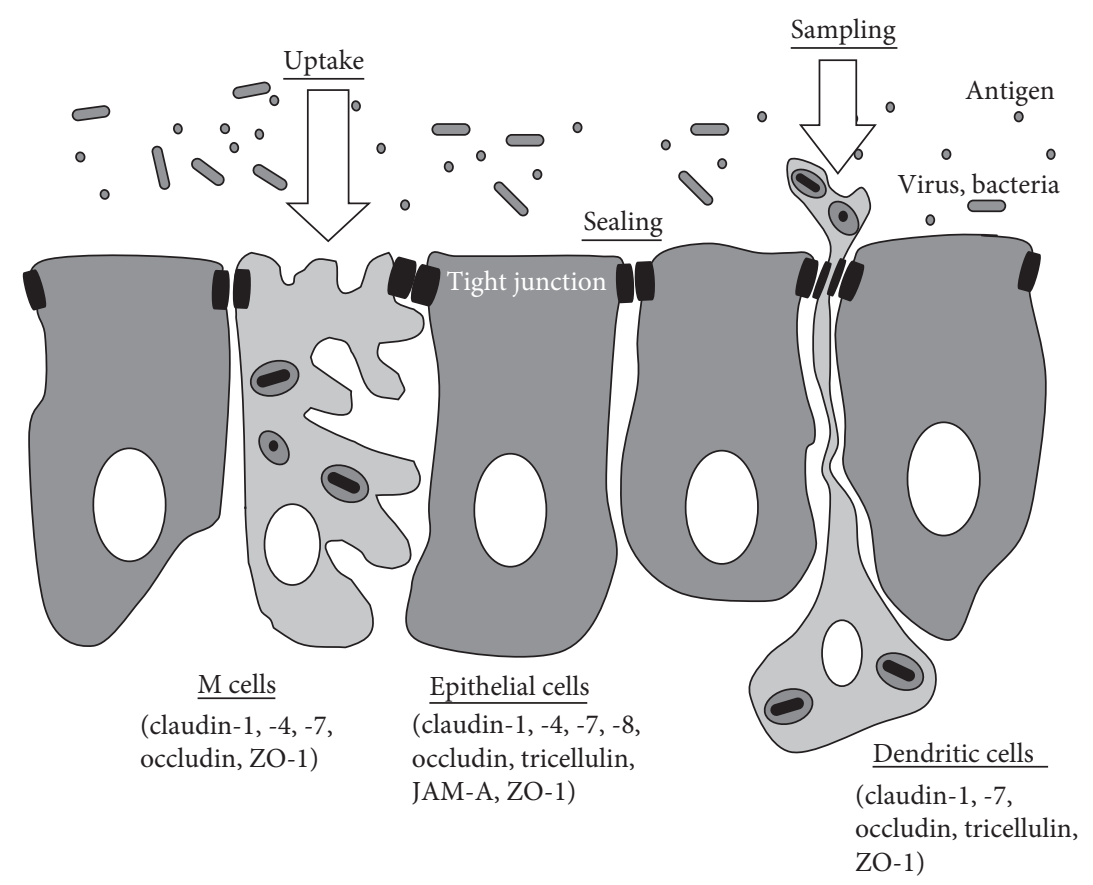

FIGURE 1: Schema of putative sealing intercellular spaces by tight junction molecules in the upper airway epithelium including epithelial cells, $\mathrm{M}$ cells, and dendritic cells.

Tight junctions are formed by not only the integral membrane proteins claudins, occludin, and JAMs, but also many peripheral membrane proteins, including the scaffold PDZ expression proteins zonula occludens (ZO)-1, ZO-2, ZO3, multi-PDZ domain protein-1 (MUPP1), and membraneassociated guanylate kinase with inverted orientation-1 (MAGI)-1, MAGI-2, MAGI-3, and cell polarity molecules ASIP/PAR-3, PAR-6, PALS-1, and PALS-1 associated tight junction (PATJ), and the non-PDZ-expressing proteins, cingulin, symplekin, ZONAB, GEF-H1, aPKC, PP2A, Rab3b, Rab13, PTEN, and 7 H6 [16-18]. Zonula occludens-1 (ZO1 ), ZO-2, and ZO-3 are members of the membrane-associated guanylate kinase (MAGUK) family of proteins displaying a characteristic multidomain structure comprised of $\mathrm{SH}$, guanylate kinase-like (GUK), and multiple PDZ (PSD95Dlg-ZO1) domains [19]. ZO-1 and ZO-2 are also closely associated with polymerization of claudins [20]. Tricellulin is first identified at tricellular contacts where there are three epithelial cells and is shown to have a barrier function [21]. More recently, lipolysis-stimulated lipoprotein receptor (LSR) is found as a tricellular tight junction-associated membrane protein and recruits tricellulin to tricellular tight junctions [22].

The claudin family, which consists of at least 27 members, is solely responsible for forming tight junction strands and has four transmembrane domains and two extracellular loops $[17,23]$. The first extracellular loop is the coreceptor of hepatitis $C$ virus [24] and influences the paracellular charge selectivity [25], and the second extracellular loop is the receptor of Clostridium perfringens enterotoxin (CPE) [26].
In addition, as claudin-4 is also a high-affinity receptor of CPE [27], full-length CPE with a direct cytotoxic effect and the C-terminal receptor binding domain of CPE (C-CPE) without a cytotoxic effect are employed for selective treatment and drug delivery against claudin-4 expressing cells [28, 29].

Occludin, the first discovered integral membrane protein of tight junctions, is most ubiquitously expressed at the apicalmost basolateral membranes and is the most reliable immunohistochemical marker for tight junctions [17, 30]. Overexpression of occludin increases the barrier function, indicated as an increase in transepithelial electric resistance (TER) increase in mammalian epithelial cells [31, 32]. However, TJ strands can be formed without occludin in some cell types, including occludin-deficient embryonic stem cells [33, 34]. Moreover, an occludin-deficient mouse model does not display a perturbation of epithelial barrier function, although a complex pathophysiological phenotype is observed with growth retardation, chronic inflammation and hyperplasia of the gastric epithelium, calcification in the brain, testicular atrophy, loss of cytoplasmic granules in striated duct cells of the salivary gland, and thinning of the compact bone [35].

JAMs (JAM-A, -B, -C, -4) are immunoglobulin superfamily proteins expressed at cell junctions in epithelial and endothelial cells as well as on the surfaces of leukocytes, platelets and erythrocytes [36]. They are important for a variety of cellular processes, including tight junction assembly, leukocyte transmigration, platelet activation, angiogenesis, and adenovirus binding. Current evidence indicates that JAM-A dimerization is necessary for functional regulation of barrier [37]. 
TABLE 1: Changes of tight junction proteins and barrier function in HNECs in vitro.

\begin{tabular}{|c|c|c|c|}
\hline \multicolumn{2}{|c|}{ Treatments } & \multirow{2}{*}{ 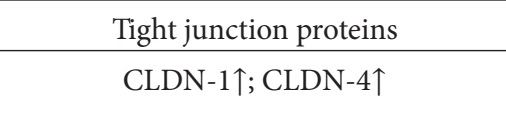 } & \multirow{2}{*}{$\begin{array}{c}\text { Barrier function } \\
\text { Upregulation }\end{array}$} \\
\hline & & & \\
\hline Growth factor & TGF- $\beta$ & 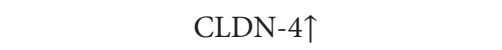 & No change \\
\hline PKC activator & TPA & 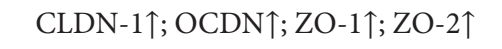 & Upregulation \\
\hline PPAR $\gamma$ ligands & $\begin{array}{l}\text { Rosiglitazone } \\
\text { Troglitazone }\end{array}$ & 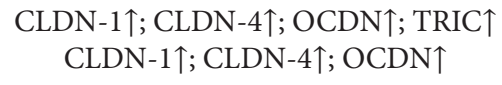 & Upregulation \\
\hline TLR3 ligand & Poly I:C & $J A M-A \downarrow$ & No change \\
\hline Cytokine & TSLP & 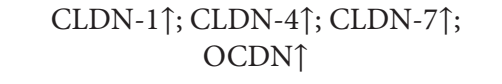 & Upregulation \\
\hline Virus & RSV & 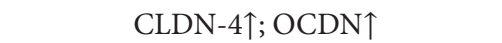 & Upregulation \\
\hline
\end{tabular}

\section{Expression and Localization of Tight Junction Molecules and Its Function in the Epithelium of the Upper Respiratory In Vivo and In Vitro}

We investigated the expression and localization of tight junction molecules and its function in the epithelium of the upper respiratory in vivo and in vitro (Figures 2 and 3) [38-44].

In human nasal mucosa in vivo in which was observed many cilia on the surface, mRNAs of occludin, JAM-A, ZO1, ZO-2, claudin-1, -4, -7, -8, -12,-13,-14, and tricellulin are detected $[38,41]$. Occludin, JAM-A, and ZO-1 were found in the uppermost layer. Claudin-1 was observed in the uppermost and basal layers in the epithelium. Claudin- 4 and -7 were observed throughout the epithelium. In freeze-fracture replicas, continuous lines of tight junction strands formed well-developed networks on the subapical membranes.

It is known that the proliferation and storage of epithelial cells in primary cultures are very limited. We introduced the catalytic component of telomerase, the hTERT gene, into primary cultured human nasal epithelial cells [39]. The ectopic expression of hTERT in the epithelial cells resulted in greater growth potential and a longer lifespan of the cells. The cells had a small cobblestone appearance in phase-contrast images. The cilia-like structures, a differentiation marker of nasal epithelial cells, were observed on the surface of hTERTtransfected cells (Figure 1). The properties of the passaged hTERT-transfected cells were similar to those of the cells in primary cultures [39].

We investigated tight junctions in hTERT-HNECs compared to primary cultured cells $[39,40]$. In both hTERTHNECs and primary cultured cells, mRNAs of claudin-1, $-2,-4,-5,-6,-7,-8,-9$, and -12 , occludin, and JAM-A were detected. Claudin-1, -4, occludin, and JAM-A were observed at cell borders cells. The continuous lines of tight junction strands formed well-developed networks on the subapical membranes. In HNECs in vitro using primary cultures and our established culture systems, tight junction molecules and the barrier function are upregulated by various stimuli (Table 1). The hTERT-transfected human nasal epithelial cells (hTERT-HNECs) can be used as an indispensable and stable model for studying regulation of tight junctions in human nasal epithelium.

\section{Tight Junctions of $M$ Cells in the Epithelium of the Upper Respiratory}

$\mathrm{M}$ cells (membranous or microfold cells) are known as specialized epithelial cells of the follicle-associated epithelium (FAE), and the role seems to be the rapid uptake of particular antigens and microorganisms to the immune cells of the lymphoid follicle to induce an effective immune response [45]. The structure and functional peculiarities of $\mathrm{M}$ cells are observed in different species and at different sites of the lymphoid tissue along the digestive and respiratory tracts [46]. The respiratory $M$ cells act as a nasopharynxassociated lymphoid tissue in the upper respiratory tract [3]. Furthermore, claudin-1, -3 , and ZO-1 are detected in $\mathrm{M}$ cells of mouse intestinal follicle-associated epithelium (FAE) [47].

The adenoidal epithelium, including $M$ cells, which are specialized for antigen uptake, forms a continuous barrier against a wide variety of exogenous antigens [48]. Several markers such as lectin histochemistry and immunoreactivity to vimentin, cytokeratins, and annexin- $\mathrm{V}$ have been proposed to identify $M$ cells in the mouse, rat, hamster, rabbit, and pig [45, 46, 49-51]. In the nasopharyngeal tonsil of the horse, lectin GS-1 B4 (Griffonia simplicifolia 1 isolectin B4) has been used as a marker for $M$ cells [52]. It was reported that cytokeratin20 (Ck20) could serve as an M cell marker for rabbit palatine tonsils [53]. In humans, clusterin is expressed in $\mathrm{M}$ cells and follicular dendritic cells at inductive sites of human mucosa-associated lymphoid tissue [54]. Class II beta-tubulin is a specific histochemical marker for human tonsillar M cells and follicular dendritic cells [55]. However, universal markers for human $M$ cells have not yet been established.

We identified M-like cells using an anti-Ck20 antibody in human adenoidal tissues in vivo and in vitro and investigated the expression of tight junctions (Figure 3) [5]. In human adenoidal epithelium in vivo, some M-like cells, characterized by irregular microvilli, were observed on the surface. Some Ck20-positive cells were randomly observed in the epithelium and appeared as pocket-like structures. In both Ck20positive and -negative cells of the adenoidal epithelium in vivo, occludin, ZO-1, claudin-1, and -7 were observed. In the primary cultures, Ck20-positive cells took up fluorescent 


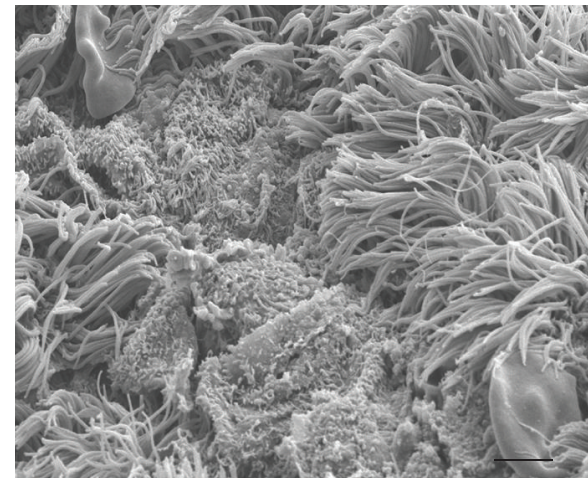

(a)
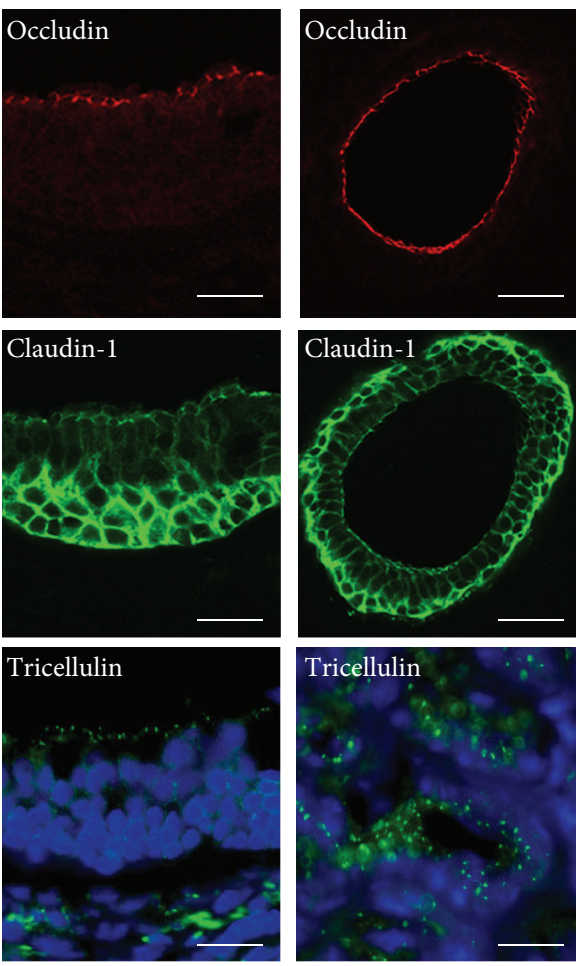

(b)

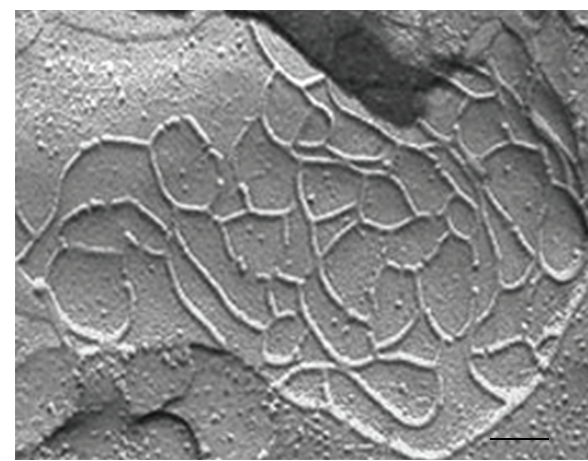

(c)

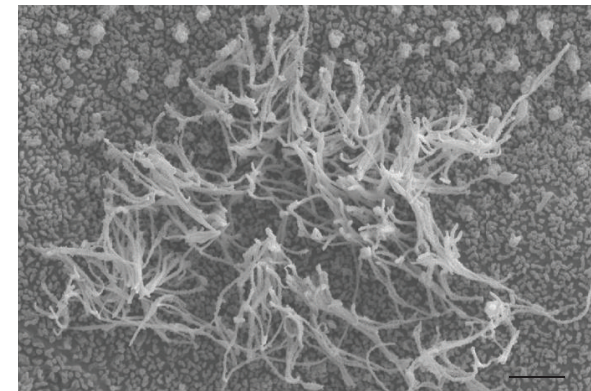

(d)

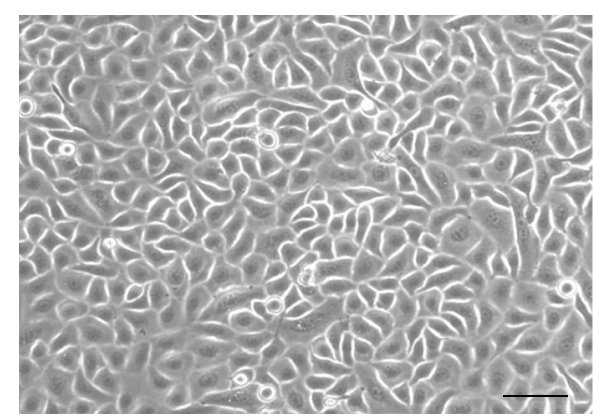

(e)
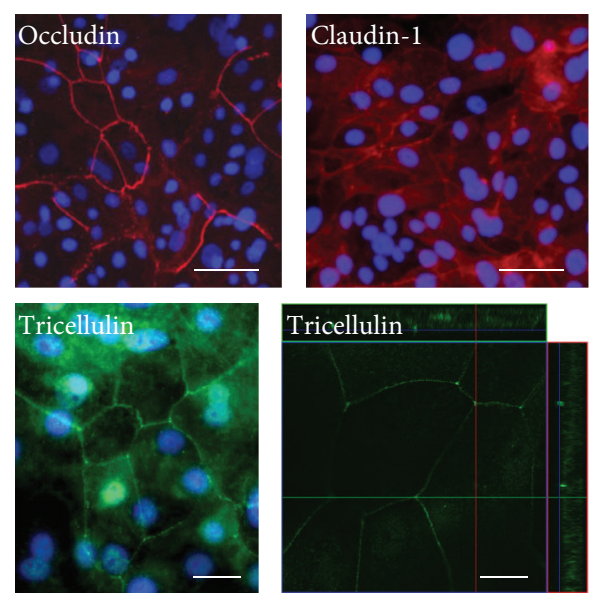

(f)

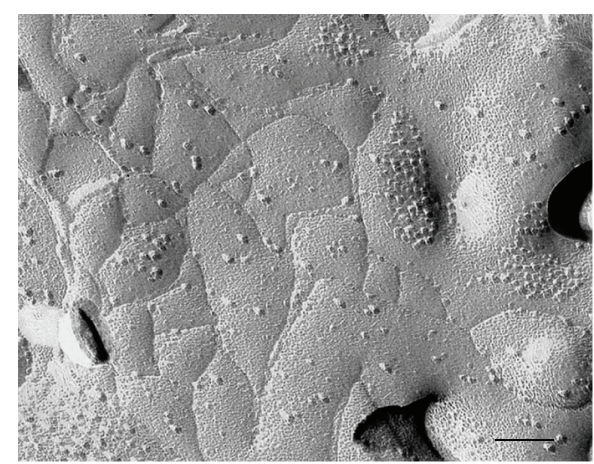

(g)

FIGURE 2: SEM image (a), immunostaining (b) for occludin, claudin-1 and tricellulin, and freeze-fracture image (c) in human nasal mucosa in vivo. Scanning electron microscopy (SEM) image (d), phase contrast (e), immunostaining (f) for occludin, claudin-1 and tricellulin, and freeze-fracture image (g) in human nasal epithelial cells in vitro (hTERT-HNECs). Scale bars: (a) and (d) $=800 \mathrm{~nm},(\mathrm{~b})$ and (f) $=10 \mu \mathrm{m},(\mathrm{c})$ and $(\mathrm{g})=200 \mathrm{~nm}$, and $(\mathrm{e})=20 \mu \mathrm{m}$. 


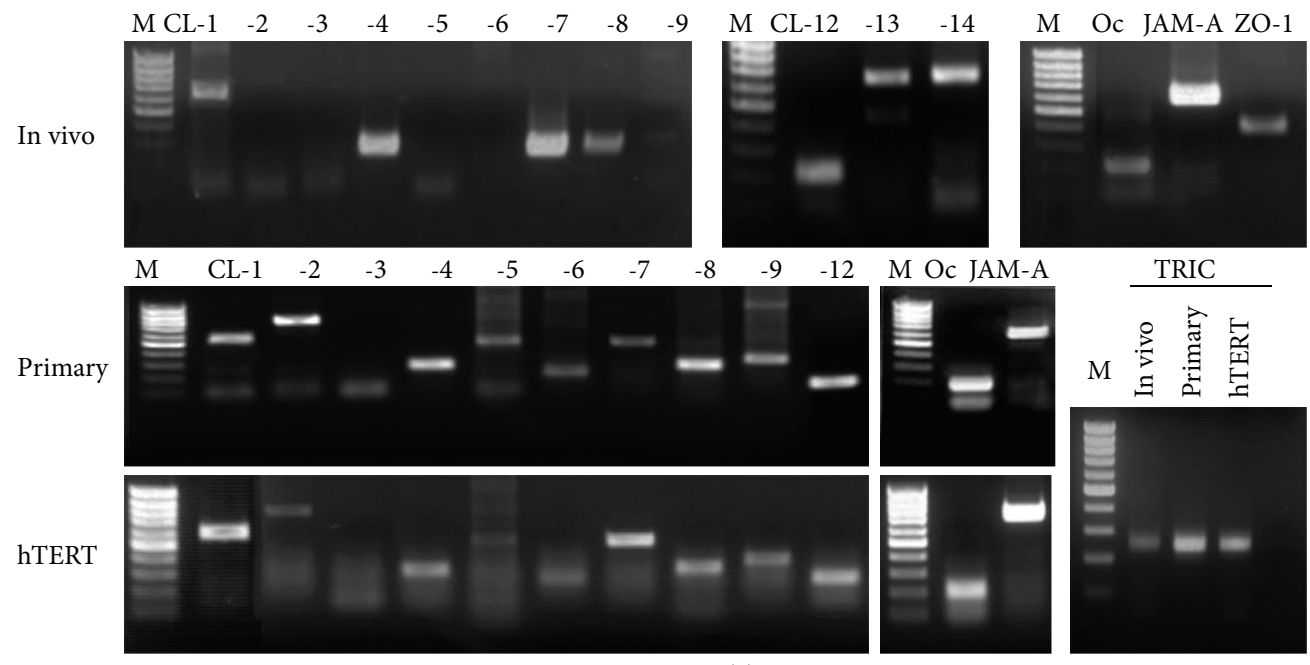

(a)

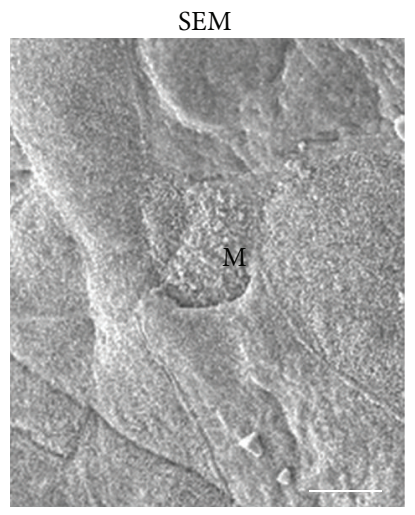

(b)

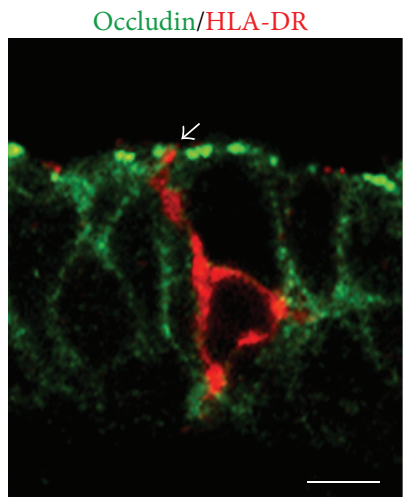

(e)

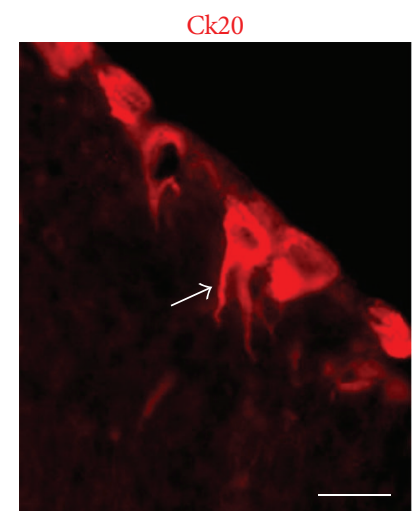

(c)

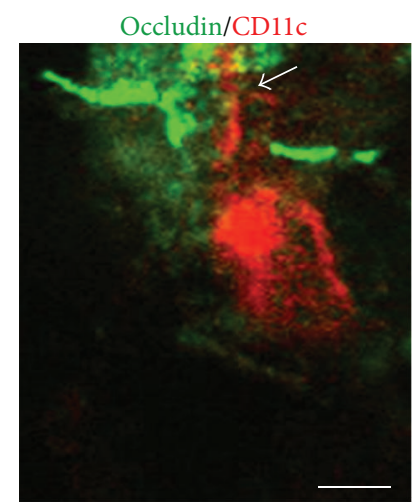

(f)

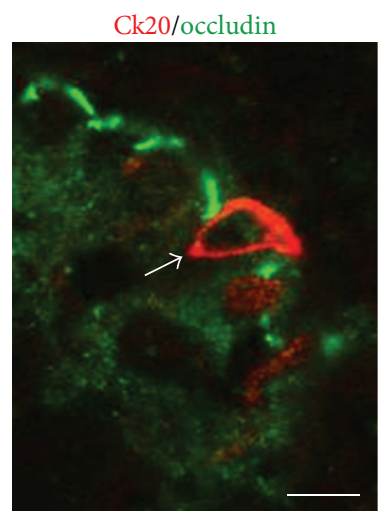

(d)

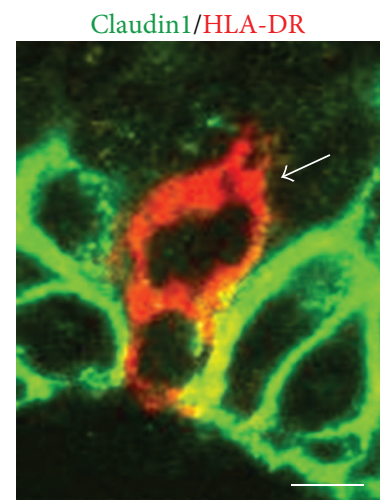

(g)

FIGURE 3: RT-PCR (a) for mRNAs of tight junction molecules in human nasal mucosa in vivo and two types of human nasal epithelial cells in vitro (primary and hTERT-HNECs). M, 100-bp ladder DNA marker; Oc, occludin; CL, claudin. SEM image (b) and immunostaining for Ck20 (c), Ck20, and occludin (d) in human adenoidal epithelium in vivo. Immunostaining for occludin and HLA-DR (e), occludin and CD11c (f), and claudin-1 and HLA-DR (g) in human nasal epithelium in vivo. M: M-like cell. Scale bars: (a) $=20 \mu \mathrm{m},(\mathrm{b})=5 \mu \mathrm{m},(\mathrm{c})$ and (d) $=20 \mu \mathrm{m}$, and $(\mathrm{e})-(\mathrm{g})=10 \mu \mathrm{m}$.

microparticles in vitro. In both Ck20-positive and -negative cells of primary cultures in vitro, occludin, ZO-1, claudin-1, and -7 were clearly observed at cell borders. These findings indicated that $M$ cells in the adenoid could take up antigens while maintaining a continuous barrier.

\section{Tight Junctions of Dendritic Cells in the Epithelium of the Upper Respiratory}

This function requires DCs, professional antigen-presenting cells that act as peripheral sentinels specializing in 
the uptake, processing, and presentation of antigenic material.

Rescigno et al. discovered a new mechanism for pathogen uptake in the mucosa by which DCs open the tight junctions between epithelial cells and send dendrites outside the epithelium to directly sample the pathogen. DCs express tight junction proteins such as occludin, claudin-1, and ZO-1 to preserve the integrity of the epithelial barrier [56].

The epithelial DC population expresses high levels of the Langerhans cell (LC) marker langerin and the tight junction proteins claudin-1, -7, and ZO-2 [57]. Claudin-1 is detected in murine $\mathrm{CD} 207^{+} \mathrm{LCs}$ residing in the epidermis but not in other skin DCs [58]. In human THP-1 monocytes, mRNAs of occludin, tricellulin, JAM-A, ZO-1, ZO-2, and claudin $-4,-7,-8$, and -9 can be detected. In mature DCs that have dendrites elongated by treatment with IL-4, GM-CSF, TNF$\alpha$, and ionomycin, mRNA and protein of JAM-A are significantly increased compared to monocytes [59]. We previously reported that in mouse XS52 DCs, claudin-1, -3, -4, -6, -7, -8 , and occludin are detected and claudin-7 is induced via an NF- $\kappa \mathrm{B}$ pathway by thymic stromal lymphopoietin (TSLP) and ligands of Toll-like receptor 2 (TLR2), TLR4, or TLR7/8 [60].

In the human nasal mucosa of allergic rhinitis, HLADR-, and CD11c-positive DCs express tight junction protein claudin-1 and penetrate beyond the apicalmost tight junction protein occludin to minimize the increase in permeability of the epithelial barrier (Figure 3) [38, 61].

\section{TLR3 Ligand Reduced Tight Junctions in the Epithelium of the Upper Respiratory}

TLRs are a component of the innate immune system [62, 63]. They enable the host to recognize a large number of pathogen-associated molecular patterns such as those of bacterial lipopolysaccharides (LPS), viral RNA, CpG-containing DNA, and flagellin, among others [64]. TLRs are also expressed in the epithelium of the upper respiratory and may play a vital role in the immunological outcomes in these tissues, which produce proinflammatory cytokines and chemokines upon ligation [65].

In human nasal epithelium in vivo and in vitro, mRNAs for all 10 known human TLRs are detected in vivo and vitro [66]. TLR3 recognizes viral double-stranded (dsRNA) and its synthetic analogue polyinosinic-polycytidylic acid (poly(I:C)) and stimulates innate immune responses [67]. In primary cultures of human adenoid epithelial cells that expressed mRNAs of TLR1, 2, 3, 4, 6, 7, and 10, stimulation by the TLR3 ligand poly(I:C), induced production of not only TNF $\alpha$ and IL- 8 but also reduced JAM-A expression. The changes were regulated via distinct signaling transduction pathways [44].

The control of TLR3-mediated signaling pathways in human nasal epithelium may be important not only in infection by viral dsRNA but also in autoimmune diseases caused by endogenous dsRNA released from necrotic cells.

\section{TSLP Induced Tight Junctions in the Epithelium of the Upper Respiratory}

The epithelial-derived factor TSLP is an IL-7-like cytokine that potently induces deregulation of Th2 responses, a hallmark feature of allergic inflammatory diseases such as asthma, atopic dermatitis, and allergic rhinitis [42, 6870]. TSLP-stimulated $\mathrm{CD}_{11 \mathrm{c}^{+}} \mathrm{DCs}$ induce naïve $\mathrm{CD} 4^{+} \mathrm{T}$ cells to differentiate into Th2 cells that produce IL-4, IL5 , IL-13, and TNF- $\alpha$ [69]. We found high expression of TSLP in epithelium from patients with allergic rhinitis with recruitment and infiltration of $\mathrm{CD}_{11 \mathrm{c}^{+}} \mathrm{DCs}$ [42]. In vitro, TSLP was significantly produced in HNECs by treatment with a TLR2 ligand Pam $_{3}$ Cys-Ser-(Lys) ${ }_{4}$ and a mixture of IL$1 \beta$ and TNF- $\alpha$. Treatment with TSLP rapidly enhanced the barrier function of cultured HNECs together with an increase of tight junction proteins claudin-1, -4, -7, and occludin. The nasal epithelial-derived TSLP not only activates DCs but also preserves the epithelial barrier via upregulation of tight junction proteins to regulate antigen sensitization during the early stage of allergic rhinitis.

\section{The Effects of Lymphocytes on Tight Junctional Barrier of the Upper Respiratory}

Chronic rhinosinusitis (CRS) is characterized by mucosal inflammation involving both the nasal cavity and paranasal sinuses [71]. The patients with chronic rhinosinusitis and nasal polyps have a Th2-predominant type of inflammation [72]. The leaky epithelium is present in vivo and in vitro in patients with downregulation of claudin- 4 and occludin mRNA in the biopsy specimens [73]. Furthermore, the barrier function in human primary sinonasal epithelial cells is decreased by the Th1 cytokine IFN- $\gamma$ and Th 2 cytokine IL4, whereas Th17 cytokine has no effect [73].

On the other hand, B lymphocytes which are responsible for the production of IgE play a crucial role in allergic and inflammatory of upper and lower airways [74]. Nasal polyps have increased numbers of activated eosinophils, mast cells, and IgE [75]. Nasal polyp epithelium from human tissue specimens has reduced claudin-1 along the basal aspect of the mucosal layer, whereas occludin is reduced in the apical and basal epithelial zones [76]. However, the closed relationship between $B$ cells and tight junctional barrier remains still unknown.

\section{RSV Induced Tight Junctions in the Epithelium of the Upper Respiratory}

The airway epithelium, which has a well-developed barrier regulated by tight junctions, is the first line of defense during respiratory virus infection. Moreover, it is also known that tight junctions include targets or receptors of viruses such as claudin-1 and occludin as coreceptors of HCV, JAM as a reovirus receptor, and CAR as a coxsackie and adenovirus receptor [77]. In human nasal epithelial cells, rhinovirus infection decreases expression of tight junction molecules ZO-1, occludin, and claudin- 1 and reduced barrier function using primary cultures [78]. 
Control: $24 \mathrm{~h}$
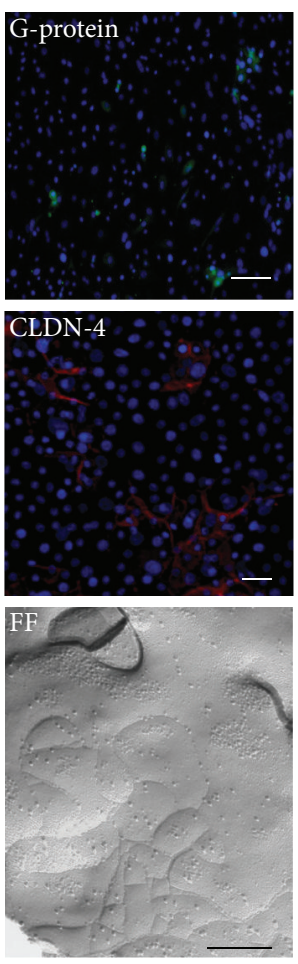

RSV: $24 \mathrm{~h}$
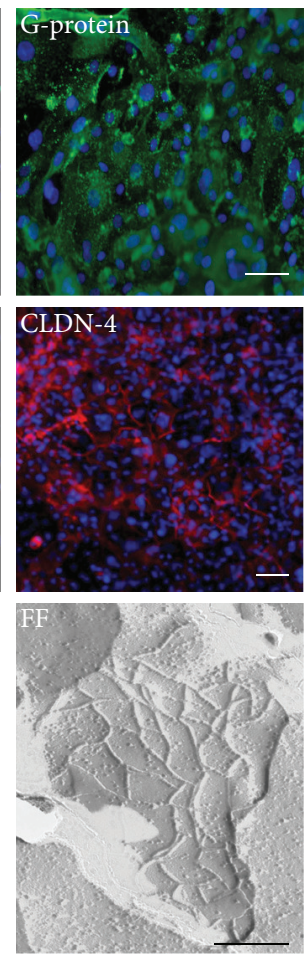

(a)

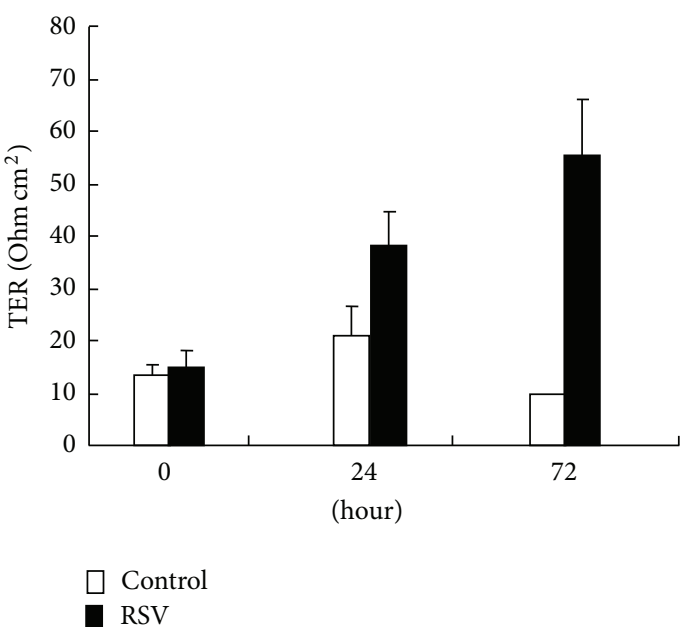

(b)

FIgURE 4: (a) Phase contrast, immunostaining for RSV/G-protein and claudin-4, and freeze-fracture image in human nasal epithelial cells in vitro (hTERT-HNECs) at $24 \mathrm{~h}$ after infection with RSV. Scale bars: white bars $=20 \mu \mathrm{m}$, black bars $=100 \mathrm{~nm}$. (b) Transepithelial electrical resistance (TER) values in hTERT-HNECs at $24 \mathrm{~h}$ after infection with RSV. $N=3,{ }^{*} P<0.01$ versus control.

On the other hand, respiratory syncytial virus (RSV) is the major cause of bronchitis, asthma, and severe lower respiratory tract disease in infants and young children [79]. To investigate the detailed mechanisms of replication and budding of RSV in human nasal epithelial cells (HNECs) and the epithelial cell responses including tight junctions, we established an RSV-infected model using hTERT-transfected HNECs [80]. When the HNECs were infected with RSV at MOI 1, the expression of RSV/G-proteins was detected in most cells by immunocytochemistry using a specific antibody (Figure 4). We found that the expression, structure and barrier function of tight junction molecules claudin- 4 and occludin were markedly induced together with production of proinflammatory cytokines IL-8 and TNF $\alpha$ in HNECs after RSV infection, and the induction of tight junction molecules possibly contributed to budding of RSV (Figure 4) [80]. However, the knockdown of claudin- 4 and occludin by siRNAs did not affect replication of RSV. The replication and budding of RSV and the epithelial cell responses in HNECs were regulated via a PKC $\delta / \mathrm{HIF}-1 \alpha / \mathrm{NF}-\kappa \mathrm{B}$ pathway [80]. The control of this pathway in HNECs may be useful not only for prevention of replication and budding of RSV but also in therapy for RSV-induced respiratory pathogenesis.

\section{Effects of C-CPE via Claudins in the Epithelium of the Upper Respiratory}

$\mathrm{COOH}$-terminal half fragment of $\mathrm{CPE}$ (C-CPE) is a nontoxic molecule that disrupts tight junction barrier function and enhances cellular absorption [81]. More recently, by screening claudin-binders from a C-CPE mutant-displaying library by using claudin-displaying budded baculovirus, a C-CPE mutant called $\mathrm{m} 19$, which bound to claudin- $-1,-2,-4$, and -5 , is made [82]. In our recent study, when HNECs were treated with wild type and $\mathrm{m} 19$ of $\mathrm{C}-\mathrm{CPE}$, the barrier function was markedly decreased at the nontoxic concentration of C-CPE and recovered without C-CPE (personal data).

\section{Conclusions}

The epithelial tight junction barrier of the upper airway epithelium, including M cells and DCs, is stably maintained via the regulation of tight junction molecules expressed in the epithelial cells, M cells, and DCs. Various antigens are sampled, transported, and released to lymphocytes through the cells while maintaining the integrity of the barrier (Figure 1).

Claudin-4 is known as a rodent $\mathrm{M}$ cell-specific gene and the high transcytotic ability of $\mathrm{M}$ cells is an attractive target 
for mucosally delivered vaccines and therapeutics $[83,84]$. Furthermore, C-CPE which is a nontoxic small molecule that disrupts tight junction barrier function can be used as a carrier for other substances to specific claudin-positive cells [81]. These may promote development of a novel strategy for drug delivery system via targeted claudins in upper airway epithelium.

Tricellular tight junctions form at the convergence of bicellular tight junctions where three epithelial cells meet in polarized epithelia, and tricellulin was the first marker of the tricellular tight junction identified in epithelial cells [21]. In various DCs, including human THP-1 cells, mouse XS52 cells, and epidermal LCs, tricellulin is also detected $[59,60]$. The tricellular tight junction may be a good penetration point for DCs into the epithelium [85]. More recently, it is reported that Shigella targets tricellular junctions including tricellulin to spread between cells via noncanonical clathrin-dependent endocytic pathway [86]. Thus, further study of tricellulin in epithelial cells and DCs of upper airway epithelium may be important to prevent invasion of inhaled environmental agents such as allergens and pathogens.

Taken together, these studies of tight junctions in upper airway epithelium should provide new insights not only into pathological conditions but also in the context of new vaccines and therapeutics against infectious and inflammatory mucosal diseases in upper airway.

\section{Acknowledgments}

The authors are grateful to Dr. Masuo Kondoh (Osaka University) for C-CPE. This work was supported by program for developing the supporting system for upgrading education and research, the Ministry of Education, Culture, Sports Science, and Technology, and the Ministry of Health, Labour and Welfare of Japan.

\section{References}

[1] S. T. Holgate, "The airway epithelium is central to the pathogenesis of asthma," Allergology International, vol. 57, no. 1, pp. $1-10,2008$.

[2] Y. Fujimura, "Evidence of M cells as portals of entry for antigens in the nasopharyngeal lymphoid tissue of humans," Virchows Archiv, vol. 436, no. 6, pp. 560-566, 2000.

[3] D. Y. Kim, A. Sato, S. Fukuyama et al., "The airway antigen sampling system: respiratory $\mathrm{M}$ cells as an alternative gateway for inhaled antigens," The Journal of Immunology, vol. 186, no. 7, pp. 4253-4262, 2011.

[4] M. C. Nawijn, T. L. Hackett, D. S. Postma, A. J. M. van Oosterhout, and I. H. Heijink, "E-cadherin: gatekeeper of airway mucosa and allergic sensitization," Trends in Immunology, vol. 32, no. 6, pp. 248-255, 2011.

[5] K. I. Takano, T. Kojima, N. Ogasawara et al., "Expression of tight junction proteins in epithelium including Ck20-positive M-like cells of human adenoids in vivo and in vitro," Journal of Molecular Histology, vol. 39, no. 3, pp. 265-273, 2008.

[6] R. M. Steinman, M. Pack, and K. Inaba, "Dendritic cells in the T-cell areas of lymphoid organs," Immunological Reviews, vol. 156, pp. 25-37, 1997.
[7] T. Yamanaka, L. Helgeland, I. N. Farstad, H. Fukushima, T. Midtvedt, and P. Brandtzaeg, "Microbial colonization drives lymphocyte accumulation and differentiation in the follicleassociated epithelium of Peyer's patches," The Journal of Immunology, vol. 170, no. 2, pp. 816-822, 2003.

[8] H. Hammad and B. N. Lambrecht, "Dendritic cells and airway epithelial cells at the interface between innate and adaptive immune responses," Allergy, vol. 66, no. 5, pp. 579-587, 2011.

[9] S. T. Holgate, "Epithelium dysfunction in asthma," Journal of Allergy and Clinical Immunology, vol. 120, no. 6, pp. 1233-1244, 2007.

[10] R. P. Schleimer, A. Kato, R. Kern, D. Kuperman, and P. C. Avila, "Epithelium: at the interface of innate and adaptive immune responses," Journal of Allergy and Clinical Immunology, vol. 120, no. 6, pp. 1279-1284, 2007.

[11] B. M. Gumbiner, "Breaking through the tight junction barrier," The Journal of Cell Biology, vol. 123, no. 6, part 2, pp. 1631-1633, 1993.

[12] E. E. Schneeberger and R. D. Lynch, "Structure, function, and regulation of cellular tight junctions," American Journal of Physiology-Lung Cellular and Molecular Physiology, vol. 262, no. 6, pp. L647-L661, 1992.

[13] G. van Meer and K. Simons, "The function of tight junctions in maintaining differences in lipid composition between the apical and the basolateral cell surface domains of MDCK cells," The EMBO journal, vol. 5, no. 7, pp. 1455-1464, 1986.

[14] M. Cereijido, J. Valdés, L. Shoshani, and R. G. Contreras, "Role of tight junctions in establishing and maintaining cell polarity," Annual Review of Physiology, vol. 60, pp. 161-177, 1998.

[15] M. S. Balda and K. Matter, "Tight junctions and the regulation of gene expression," Biochimica et Biophysica Acta, vol. 1788, no. 4, pp. 761-767, 2009.

[16] E. E. Schneeberger and R. D. Lynch, "The tight junction: a multifunctional complex," American Journal of Physiology-Cell Physiology, vol. 286, no. 6, pp. C1213-C1228, 2004.

[17] S. Tsukita, M. Furuse, and M. Itoh, "Multifunctional strands in tight junctions," Nature Reviews Molecular Cell Biology, vol. 2, no. 4, pp. 285-293, 2001.

[18] N. Sawada, M. Murata, K. Kikuchi et al., "Tight junctions and human diseases," Medical Electron Microscopy, vol. 36, no. 3, pp. 147-156, 2003.

[19] J. M. Anderson, "Cell signalling: MAGUK magic," Current Biology, vol. 6, no. 4, pp. 382-384, 1996.

[20] K. Umeda, J. Ikenouchi, S. Katahira-Tayama et al., "ZO-1 and $\mathrm{ZO}-2$ independently determine where claudins are polymerized in tight-junction strand formation," Cell, vol. 126, no. 4, pp. 741-754, 2006.

[21] J. Ikenouchi, M. Furuse, K. Furuse, H. Sasaki, S. Tsukita, and S. Tsukita, "Tricellulin constitutes a novel barrier at tricellular contacts of epithelial cells," The Journal of Cell Biology, vol. 171, no. 6, pp. 939-945, 2005.

[22] S. Masuda, Y. Oda, H. Sasaki et al., "LSR defines cell corners for tricellular tight junction formation in epithelial cells," Journal of Cell Science, vol. 124, no. 4, pp. 548-555, 2011.

[23] K. Mineta, Y. Yamamoto, Y. Yamazaki et al., "Predicted expansion of the claudin multigene family," FEBS Letters, vol. 585, no. 4, pp. 606-612, 2011.

[24] L. W. Meredith, G. K. Wilson, N. F. Fletcher, and J. A. McKeating, "Hepatitis C virus entry: beyond receptors," Reviews in Medical Virology, vol. 22, no. 3, pp. 182-193, 2012. 
[25] S. M. Krug, D. Günzel, M. P. Conrad et al., "Charge-selective claudin channels," Annals of the New York Academy Sciences, vol. 1257, no. 1, pp. 20-28, 2012.

[26] K. Fujita, J. Katahira, Y. Horiguchi, N. Sonoda, M. Furuse, and S. Tsukita, "Clostridium perfringens enterotoxin binds to the second extracellular loop of claudin-3, a tight junction integral membrane protein," FEBS Letters, vol. 476, no. 3, pp. 258-261, 2000.

[27] J. Katahira, H. Sugiyama, N. Inoue, Y. Horiguchi, M. Matsuda, and N. Sugimoto, "Clostridium perfringens enterotoxin utilizes two structurally related membrane proteins as functional receptors in vivo," The Journal of Biological Chemistry, vol. 272, no. 42, pp. 26652-26658, 1997.

[28] P. Michl, M. Buchholz, M. Rolke et al., "Claudin-4: a new target for pancreatic cancer treatment using clostridium perfringens enterotoxin," Gastroenterology, vol. 121, no. 3, pp. 678-684, 2001.

[29] R. Saeki, M. Kondoh, H. Kakutani et al., "A novel tumortargeted therapy using a claudin-4-targeting molecule," Molecular Pharmacology, vol. 76, no. 4, pp. 918-926, 2009.

[30] M. Furuse, T. Hirase, M. Itoh et al., "Occludin: a novel integral membrane protein localizing at tight junctions," The Journal of Cell Biology, vol. 123, no. 6, pp. 1777-1788, 1993.

[31] M. S. Balda, J. A. Whitney, C. Flores, S. González, M. Cereijido, and K. Matter, "Functional dissociation of paracellular permeability and transepithelial electrical resistance and disruption of the apical-basolateral intramembrane diffusion barrier by expression of a mutant tight junction membrane protein," The Journal of Cell Biology, vol. 134, no. 4, pp. 1031-1049, 1996.

[32] K. M. McCarthy, I. B. Skare, M. C. Stankewich et al., "Occludin is a functional component of the tight junction," Journal of Cell Science, vol. 109, no. 9, pp. 2287-2298, 1996.

[33] T. Hirase, J. M. Staddon, M. Saitou et al., "Occludin as a possible determinant of tight junction permeability in endothelial cells," Journal of Cell Science, vol. 110, no. 14, pp. 1603-1613, 1997.

[34] M. Saitou, K. Fujimoto, Y. Doi et al., "Occludin-deficient embryonic stem cells can differentiate into polarized epithelial cells bearing tight junctions," The Journal of Cell Biology, vol. 141, no. 2, pp. 397-408, 1998.

[35] M. Saitou, M. Furuse, H. Sasaki et al., "Complex phenotype of mice lacking occludin, a component of tight junction strands," Molecular Biology of the Cell, vol. 11, no. 12, pp. 4131-4142, 2000.

[36] I. Martìn-Padura, S. Lostaglio, M. Schneemann et al., "Junctional adhesion molecule, a novel member of the immunoglobulin superfamily that distributes at intercellular junctions and modulates monocyte transmigration," The Journal of Cell Biology, vol. 142, no. 1, pp. 117-127, 1998.

[37] A. C. Monteiro and C. A. Parkos, "Intracellular mediators of JAM-A-dependent epithelial barrier function," Annals of the New York Academy of Sciences, vol. 1257, no. 1, pp. 115-124, 2012.

[38] K. I. Takano, T. Kojima, M. Go et al., "HLA-DR- and CD11cpositive dendritic cells penetrate beyond well-developed epithelial tight junctions in human nasal mucosa of allergic rhinitis," The Journal of Histochemistry and Cytochemistry, vol. 53, no. 5, pp. 611-619, 2005.

[39] M. Kurose, T. Kojima, J. I. Koizumi et al., "Induction of claudins in passaged hTERT-transfected human nasal epithelial cells with an extended life span," Cell and Tissue Research, vol. 330, no. 1, pp. 63-74, 2007.
[40] J. I. Koizumi, T. Kojima, N. Ogasawara et al., "Protein kinase $c$ enhances tight junction barrier function of human nasal epithelial cells in primary culture by transcriptional regulation," Molecular Pharmacology, vol. 74, no. 2, pp. 432-442, 2008.

[41] T. Ohkuni, T. Kojima, N. Ogasawara et al., "Expression and localization of tricellulin in human nasal epithelial cells in vivo and in vitro," Medical Molecular Morphology, vol. 42, no. 4, pp. 204-211, 2009.

[42] R. Kamekura, T. Kojima, J. I. Koizumi et al., "Thymic stromal lymphopoietin enhances tight-junction barrier function of human nasal epithelial cells," Cell and Tissue Research, vol. 338, no. 2, pp. 283-293, 2009.

[43] N. Ogasawara, T. Kojima, M. Go et al., "PPAR $\gamma$ agonists upregulate the barrier function of tight junctions via a PKC pathway in human nasal epithelial cells," Pharmacological Research, vol. 61, no. 6, pp. 489-498, 2010.

[44] T. Ohkuni, T. Kojima, N. Ogasawara et al., "Poly(I:C) reduces expression of JAM-A and induces secretion of IL- 8 and TNF$\alpha$ via distinct NF- $\kappa$ B pathways in human nasal epithelial cells," Toxicology and Applied Pharmacology, vol. 250, no. 1, pp. 29-38, 2011.

[45] J. Mach, T. Hshieh, D. Hsieh, N. Grubbs, and A. Chervonsky, "Development of intestinal M cells," Immunological Reviews, vol. 206, pp. 177-189, 2005.

[46] A. Gebert, "The role of M cells in the protection of mucosal membranes," Histochemistry and Cell Biology, vol. 108, no. 6, pp. 455-470, 1997.

[47] A. M. Clark and B. H. Hirst, "Expression of junction-associated proteins differentiates mouse intestinal $\mathrm{M}$ cells from enterocytes," Histochemistry and Cell Biology, vol. 118, no. 2, pp. 137-147, 2002.

[48] M. J. P. van Kempen, G. T. Rijkers, and P. B. van Cauwenberge, "The immune response in adenoids and tonsils," International Archives of Allergy and Immunology, vol. 122, no. 1, pp. 8-19, 2000.

[49] P. J. Giannasca, J. A. Boden, and T. P. Monath, "Targeted delivery of antigen to hamster nasal lymphoid tissue with Mcell-directed lectins," Infection and Immunity, vol. 65, no. 10, pp. 4288-4298, 1997.

[50] T. Kucharzik, N. Lügering, K. W. Schmid, M. A. Schmidt, R. Stoll, and W. Domschke, "Human intestinal M cells exhibit enterocyte-like intermediate filaments," Gut, vol. 42, no. 1, pp. 54-62, 1998.

[51] P. Verbrugghe, W. Waelput, B. Dieriks, A. Waeytens, J. Vandesompele, and C. A. Cuvelier, "Murine M cells express annexin V specifically," Journal of Pathology, vol. 209, no. 2, pp. 240-249, 2006.

[52] P. Kumar and J. F. Timoney, "Light and electron microscope studies on the nasopharynx and nasopharyngeal tonsil of the horse," Anatomia, Histologia, Embryologia, vol. 30, no. 2, pp. 77-84, 2001.

[53] A. Carapelli, M. Regoli, C. Nicoletti, L. Ermini, L. Fonzi, and E. Bertelli, "Rabbit tonsil-associated M-cells express cytokeratin 20 and take up particulate antigen," The Journal of Histochemistry and Cytochemistry, vol. 52, no. 10, pp. 1323-1331, 2004.

[54] P. Verbrugghe, P. Kujala, W. Waelput, P. J. Peters, and C. A. Cuvelier, "Clusterin in human gut-associated lymphoid tissue, tonsils, and adenoids: localization to $\mathrm{M}$ cells and follicular dendritic cells," Histochemistry and Cell Biology, vol. 129, no. 3, pp. 311-320, 2008. 
[55] J. H. Lee, S. K. Kong, Z. S. Wu et al., "Class II $\beta$-tubulin is a novel marker for human tonsillar $M$ cells and follicular dendritic cells," Journal of Oral Pathology and Medicine, vol. 39, no. 7, pp. 533-539, 2010.

[56] M. Rescigno, M. Urbano, B. Valzasina et al., "Dendritic cells express tight junction proteins and penetrate gut epithelial monolayers to sample bacteria," Nature Immunology, vol. 2, no. 4, pp. 361-367, 2001.

[57] S. S. J. Sung, S. M. Fu, C. E. Rose Jr., F. Gaskin, S. T. Ju, and S. R. Beaty, "A major lung CD103 $(\alpha \mathrm{E})-\beta 7$ integrin-positive epithelial dendritic cell population expressing langerin and tight junction proteins," The Journal of Immunology, vol. 176, no. 4, pp. 2161-2172, 2006.

[58] S. C. Zimmerli and C. Hauser, "Langerhans cells and lymph node dendritic cells express the tight junction component claudin-1," Journal of Investigative Dermatology, vol. 127, no. 10, pp. 2381-2390, 2007.

[59] N. Ogasawara, T. Kojima, M. Go et al., "Induction of JAMA during differentiation of human THP-1 dendritic cells," Biochemical and Biophysical Research Communications, vol. 389, no. 3, pp. 543-549, 2009.

[60] R. Kamekura, T. Kojima, A. Takashima et al., "Thymic stromal lymphopoietin induces tight junction protein claudin-7 via NF$\kappa \mathrm{B}$ in dendritic cells," Histochemistry and Cell Biology, vol. 133, no. 3, pp. 339-348, 2010.

[61] N. Ogasawara, T. Kojima, M. Go et al., "Epithelial barrier and antigen uptake in lymphoepithelium of human adenoids," Acta Oto-Laryngologica, vol. 131, no. 2, pp. 116-123, 2011.

[62] A. Iwasaki and R. Medzhitov, "Toll-like receptor control of the adaptive immune responses," Nature Immunology, vol. 5, no. 10, pp. 987-995, 2004.

[63] K. Takeda and S. Akira, "Toll-like receptors in innate immunity," International Immunology, vol. 17, no. 1, pp. 1-14, 2005.

[64] T. Kawai and S. Akira, "TLR signaling," Cell Death and Differentiation, vol. 13, no. 5, pp. 816-825, 2006.

[65] M. J. Lange, J. C. Lasiter, and M. L. Misfeldt, “Toll-like receptors in tonsillar epithelial cells," International Journal of Pediatric Otorhinolaryngology, vol. 73, no. 4, pp. 613-621, 2009.

[66] M. J. Lesmeister, M. R. Bothwell, and M. L. Misfeldt, "Tolllike receptor expression in the human nasopharyngeal tonsil (adenoid) and palantine tonsils: a preliminary report," International Journal of Pediatric Otorhinolaryngology, vol. 70, no. 6, pp. 987-992, 2006.

[67] L. Alexopoulou, A. C. Holt, R. Medzhitov, and R. A. Flavell, "Recognition of double-stranded RNA and activation of NF- $\kappa \mathrm{B}$ by Toll-like receptor 3," Nature, vol. 413, no. 6857, pp. 732-738, 2001.

[68] S. T. Holgate, "Epithelium dysfunction in asthma," Journal of Allergy and Clinical Immunology, vol. 120, no. 6, pp. 1233-1244, 2007.

[69] V. Soumelis, P. A. Reche, H. Kanzler et al., "Human epithelial cells trigger dendritic cell-mediated allergic inflammation by producing TSLP," Nature Immunology, vol. 3, no. 7, pp. 673-680, 2002.

[70] S. Ying, B. O'Connor, J. Ratoff et al., "Thymic stromal lymphopoietin expression is increased in asthmatic airways and correlates with expression of Th2-attracting chemokines and disease severity," The Journal of Immunology, vol. 174, no. 12, pp. 8183-8190, 2005.
[71] B. F. Marple, J. A. Stankiewicz, F. M. Baroody et al., "Diagnosis and management of chronic rhinosinusitis in adults," Postgraduate Medicine, vol. 121, no. 6, pp. 121-139, 2009.

[72] N. van Bruaene, C. A. Pérez-Novo, T. M. Basinski et al., “T-cell regulation in chronic paranasal sinus disease," Journal of Allergy and Clinical Immunology, vol. 121, no. 6, pp. 1435.e3-1441.e3, 2008.

[73] M. B. Soyka, P. Wawrzyniak, T. Eiwegger et al., "Defective epithelial barrier in chronic rhinosinusitis:the regulation of tight junctions by IFN- $\gamma$ and IL-4," Journal of Allergy and Clinical Immunology. In press.

[74] J. P. Drolet, H. Frangie, J. Guay, O. Hajoui, Q. Hamid, and B. D. Mazer, "B lymphocytes in inflammatory airway diseases," Clinical and Experimental Allergy, vol. 40, no. 6, pp. 841-849, 2010.

[75] M. S. Georgy and A. T. Peters, "Nasal polyps," in Allergy and Asthma Proceedings, vol. 33, chapter 7, supplement 1, pp. 22-23, 2012.

[76] G. A. Rogers, K. Den Beste, C. A. Parkos, A. Nusrat, J. M. Delgaudio, and S. K. Wise, "Epithelial tight junction alterations in nasal polyposis," International Forum of Allergy and Rhinology, vol. 1, no. 1, pp. 50-54, 2011.

[77] J. A. Guttman and B. B. Finlay, "Tight junctions as targets of infectious agents," Biochimica et Biophysica Acta, vol. 1788, no. 4, pp. 832-841, 2009.

[78] N. K. Yeo and Y. J. Jang, "Rhinovirus infection-induced alteration of tight junction and adherens junction components in human nasal epithelial cells," The Laryngoscope, vol. 120, no. 2, pp. 346-352, 2010.

[79] V. Bitko and S. Barik, "Persistent activation of RelA by respiratory syncytial virus involves protein kinase $\mathrm{C}$, underphosphorylated $\mathrm{I} \kappa \mathrm{B} \beta$, and sequestration of protein phosphatase $2 \mathrm{~A}$ by the viral phosphoprotein," Journal of Virology, vol. 72, no. 7, pp. 5610-5618, 1998.

[80] T. Masaki, T. Kojima, T. Okabayashi et al., "A nuclear factor- $\kappa \mathrm{B}$ signaling pathway via protein kinase $C \delta$ regulates replication of respiratory syncytial virus in polarized normal human nasal epithelial cells," Molecular Biology of the Cell, vol. 22, no. 13, pp. 2144-2156, 2011.

[81] N. Sonoda, M. Furuse, H. Sasaki et al., "Clostridium perfringens enterotoxin fragment removes specific claudins from tight junction strands: evidence for direct involvement of claudins in tight junction barrier," The Journal of Cell Biology, vol. 147, no. 1, pp. 195-204, 1999.

[82] K. Matsuhisa, M. Kondoh, H. Suzuki, and K. Yagi, “Comparison of mucosal absorption-enhancing activity between a claudin3/-4 binder and a broadly specific claudin binder," vol. 423, no. 2, pp. 229-233, 2012.

[83] J. Wang, M. Lopez-Fraga, A. Rynko, and D. D. Lo, “TNFR and LT $\beta$ R agonists induce follicle-associated epithelium and M cell specific genes in rat and human intestinal epithelial cells," Cytokine, vol. 47, no. 1, pp. 69-76, 2009.

[84] T. E. Rajapaksa, M. Stover-Hamer, X. Fernandez, H. A. Eckelhoefer, and D. D. Lo, "Claudin 4-targeted protein incorporated into PLGA nanoparticles can mediate M cell targeted delivery," Journal of Controlled Release, vol. 142, no. 2, pp. 196-205, 2010.

[85] A. Kubo, K. Nagao, M. Yokouchi, H. Sasaki, and M. Amagai, "External antigen uptake by Langerhans cells with reorganization of epidermal tight junction barriers," Journal of Experimental Medicine, vol. 206, no. 13, pp. 2937-2946, 2009. 
[86] M. Fukumatsu, M. Ogawa, S. Arakawa et al., "Shigella targets epithelial tricellular junctions and uses a noncanonical clathrindependent endocytic pathway to spread between cells," Cell Host and Microbe, vol. 11, no. 4, pp. 325-336, 2012. 


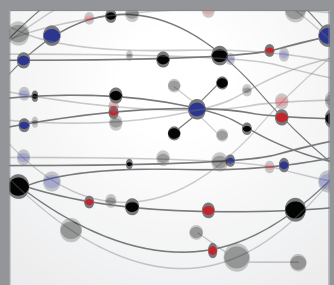

The Scientific World Journal
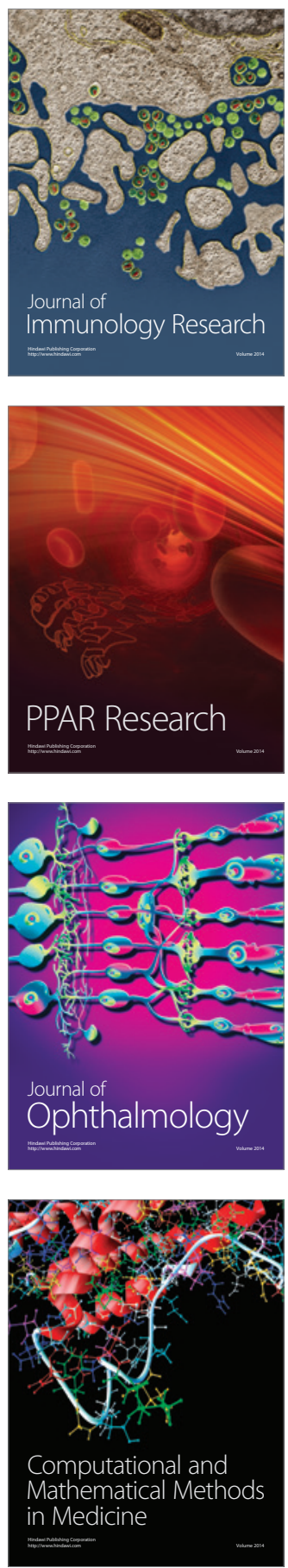

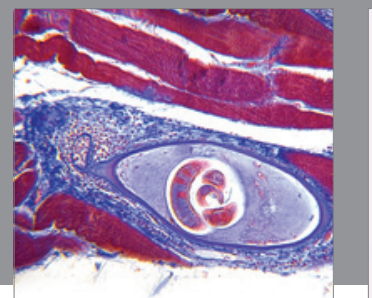

Gastroenterology

Research and Practice
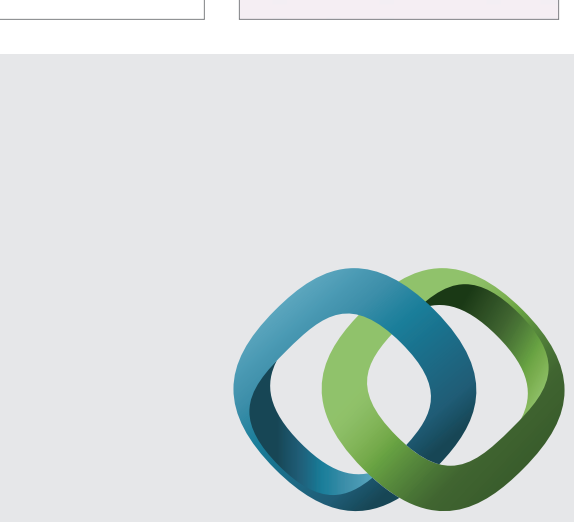

\section{Hindawi}

Submit your manuscripts at

http://www.hindawi.com
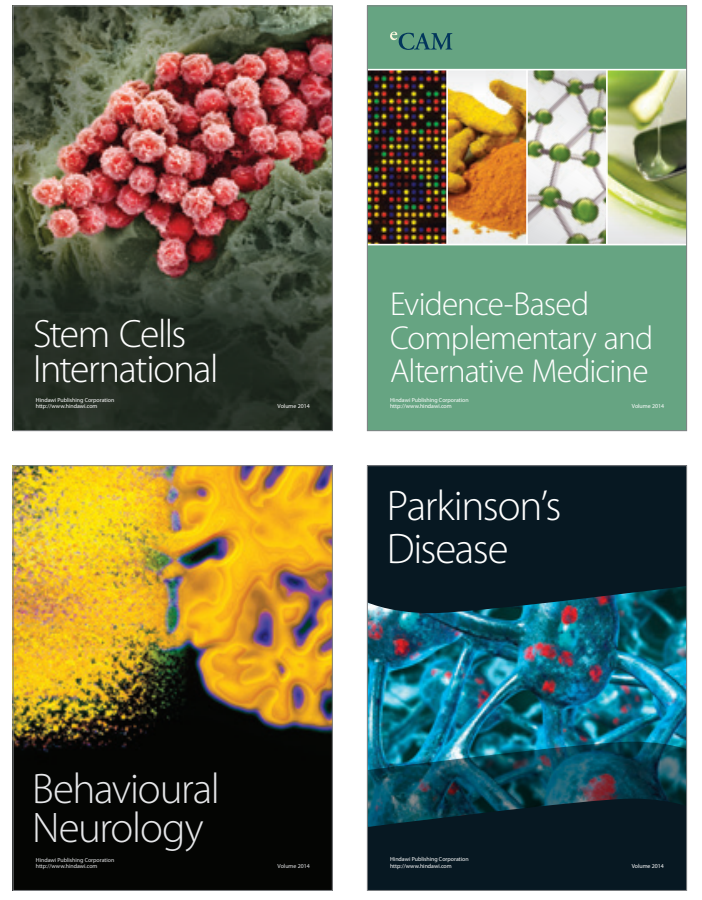
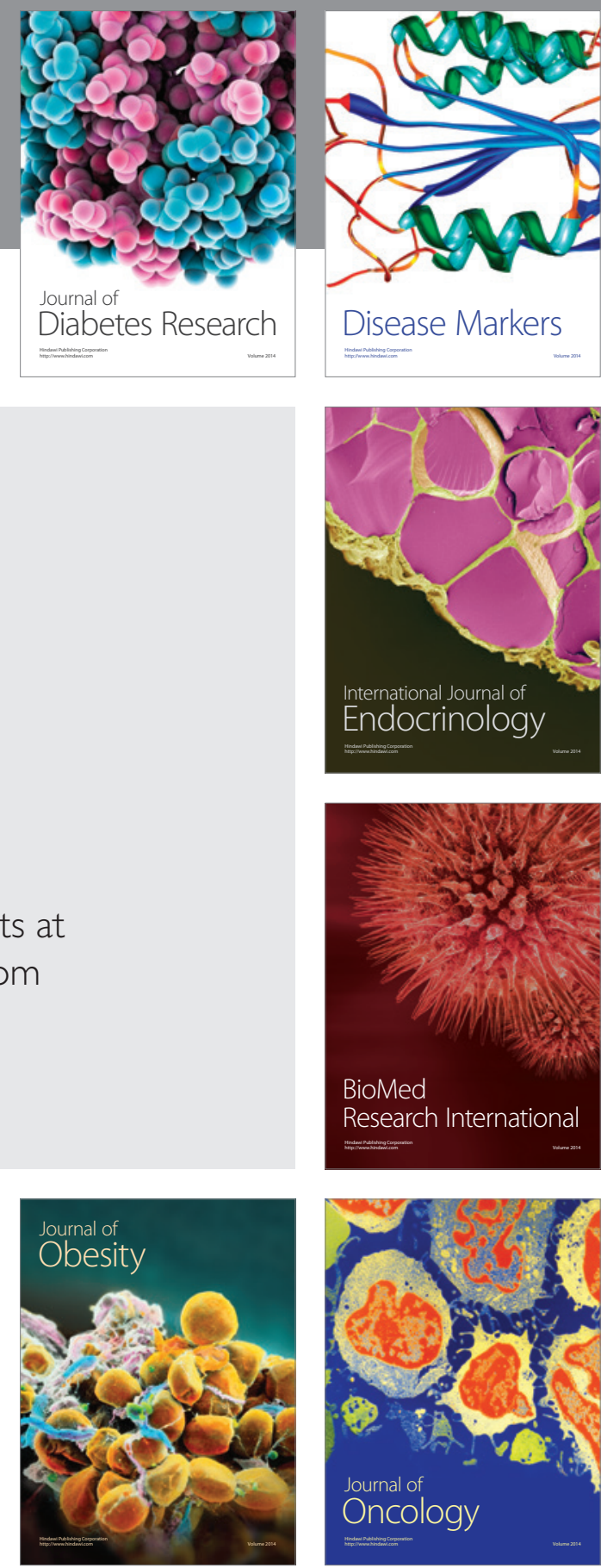

Disease Markers
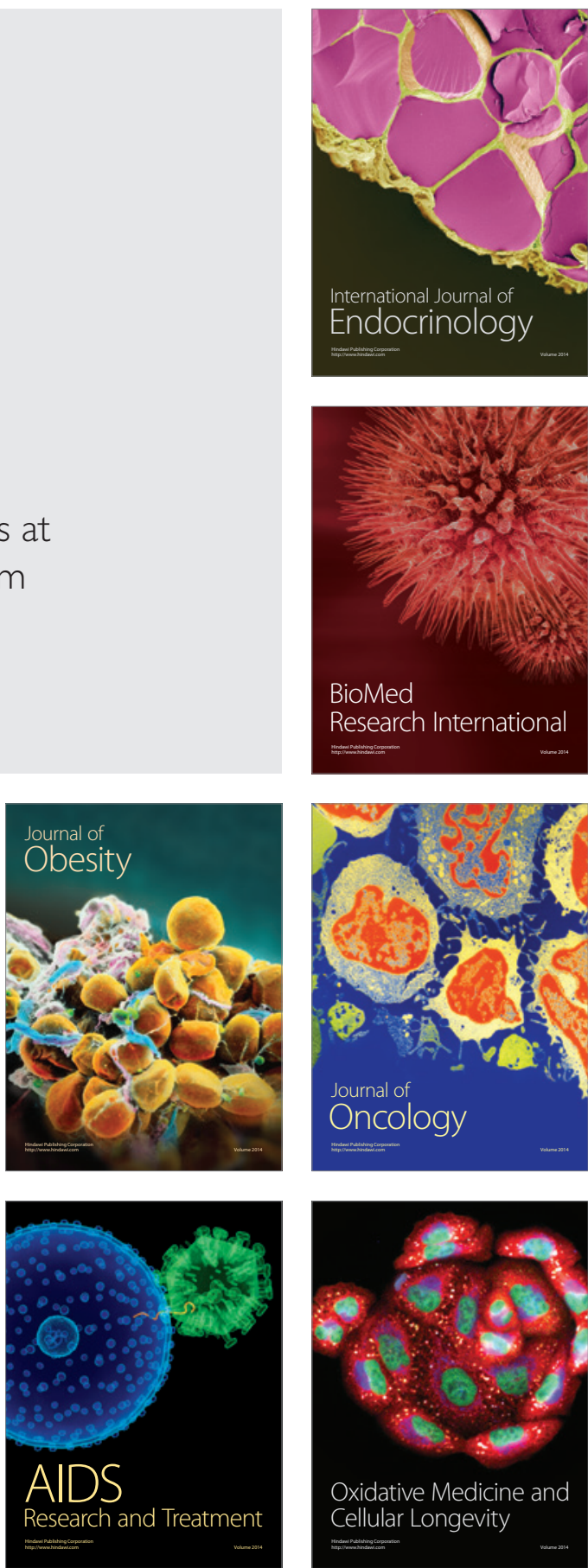